See discussions, stats, and author profiles for this publication at: https://www.researchgate.net/publication/225348470

\title{
Evaluation of the maize ( Zea mays L.) diversity on the Archipelago of Madeira
}

Article in Genetic Resources and Crop Evolution · March 2008

DOI: 10.1007/510722-007-9230-9

\section{CITATIONS}

24

7 authors, including:

Miguel Â. Almeida Pinheiro de Carvalho

Universidade da Madeira

130 PUBLICATIONS 957 CITATIONS

$$
\text { SEE PROFILE }
$$

Mario Motto

fondazione per le nuove tecnologie della vita

145 PUBLICATIONS 4,731 CITATIONS

SEE PROFILE

\section{READS}

156

\section{SEE PROALE}

Some of the authors of this publication are also working on these related projects:

SYMPOSIUM: Agriculture and Food Sustainability - New Climate Change Scenarios View project

Project MACBIOBLUE - "Transfer of Biotechnology Research to Enterprises", MAC/3/C224, (Azores, Madeira, Canary Islands, Cape Verde, Mauritânia, Senegal), cofinanced at $85 \%$ by the European Union (FEDER, MAC 2014-2020). View project 


\title{
Evaluation of the maize (Zea mays L.) diversity on the Archipelago of Madeira
}

\author{
Miguel Ângelo A. Pinheiro de Carvalho · José Filipe Teixeira Ganança • \\ Ivo Abreu · Nélia F. Sousa - Teresa M. Marques dos Santos • \\ Maria Rita Clemente Vieira $\cdot$ Mario Motto
}

Received: 13 July 2006/Accepted: 5 March 2007 / Published online: 22 May 2007

(C) Springer Science+Business Media B.V. 2007

\begin{abstract}
The variability of 43 open-pollinated populations of maize (Zea mays L.), representing a wide range of ecological conditions on the Archipelago of Madeira, was evaluated based on the morphological and reproductive traits. Individual data of 41 traits related to earliness, plant and tassel structure and the shape of the ear and grain were analysed using multivariate analysis. The populations belonging to two major maize varieties were grouped into four groups by their degree of dissimilarity, based on discriminant analysis. The dissimilarity of these groups was confirmed by the values of the Tukey test. The racial rank of these groups was proposed and a brief description of the maize landraces was presented. This work represents the first morphological characterization and analysis of diversity of maize germplasm for the Archipelago of Madeira where the traditional agricultural practices are still
\end{abstract}

M. Â. A. Pinheiro de Carvalho · J. F. T. Ganança ( $)$. I. Abreu · N. F. Sousa - T. M. M. dos Santos ISOPlexis Germplasm Bank, Centre of Studies for Macaronesia, University of Madeira, Funchal 9000-390, Portugal

e-mail: jofitei@gmail.com

M. R. Clemente Vieira

Institute of Botany, University of Coimbra, 3001-455

Coimbra, Portugal

M. Motto

Institute of Crop Cultures, 24126 Bergamo, Italy keeping this Portuguese region free from corn hybrids. The description of the Madeiran corn landraces allows us to preserve the existing corn biodiversity and could be used for their registration as conservation landraces or for conservation and breeding proposes worldwide.

Keywords Landraces identification - Maize germplasm $\cdot$ Morphological characterization $\cdot \mathrm{Zea}$ mays L.

\section{Introduction}

The Portuguese Archipelago of Madeira is located on the Atlantic Ocean, between latitudes $33^{\circ} 1032^{\circ} 20 \mathrm{~N}$ and longitudes $16^{\circ} 1017^{\circ} 20 \mathrm{~W}, 630 \mathrm{~km}$ west of the coast of North Africa, and consists of five islands: Madeira, Porto Santo, Deserta Grande, Deserta Pequena and Bugio. The main islands are Madeira with an area of $728 \mathrm{~km}^{2}$ (50 by $25 \mathrm{~km}$ ), and Porto Santo with an area of $50 \mathrm{~km}^{2}$. Madeira itself is the largest and highest of the islands, where Pico Ruivo (1,861 masl) and Pico Areeiro (1,820 masl) are the highest peaks. The agriculture is exercised by farmers, who often operate on small plots located on terraces ploughed on steep slopes of remote and isolated valleys ranging from the sea level up to about 1,000 masl. The Archipelago is of a volcanic origin, and shows specific soil and edaphic features, which have promoted adaptation of cultivars and evolution 
of local crop landraces (Pinheiro de Carvalho et al. 2003, 2004a).

Maize (Zea mays L.) was introduced to the island of Madeira in 1760 (Silva and Meneses 1984), more than 200 years after the first maize introductions in Europe (Paliwal 2000). First introductions have been made from the Archipelago of Azores, where maize had already an important crop culture (Ribeiro 2001). However, only in 1847 promoted by the improvement of the irrigation facilities maize was adopted as an agricultural crop used for human food and animal feeding in the Archipelago of Madeira (Ribeiro 2001). Since then farmers used the local market to obtain seeds for their own production and the maize germplasm introductions seem to have been episodic. During the last 160 years, documented or pointed by farmers maize introductions occurred, mainly from Azores, Canary Islands, Portugal mainland and possibly from Africa.

Since the beginning of maize cultivation on Madeira, farmers had traditionally cultivated this crop across the entire Archipelago, in diversity of environments ranging from sea level to $1,000 \mathrm{~m}$. In spite of the small size of the Archipelago, maize is cultivated under a variety of conditions that differ in pluviosity, temperature, soil, manure and intercropping conditions, and rotational practices. As a result open-pollinated cultivars belonging to two major varieties white ('Branco') and yellow ('Amarelo') maize have been acclimated to different environmental conditions, process which has promoted by the geographical isolation, topography and farmers selection criteria. At Madeira, maize is sown from late February to May, and harvested from July to the end of October, according to geographical location and specific conditions of the farmer's plots. The succeed adaptation to local conditions explains why maize is still used as crop by farmers, and their preferences for local old cultivars, which are differentiated by a number of specific morphological and agronomic traits. The use of traditional maize cultivars in Madeiran cooking avoided the replacement of local landraces by commercial hybrids, whereas they never got a successful utilization. However, recent trends, such as the reduction of rural population and abandoning of traditional agricultural practices will lead to an irreversible genetic erosion of these maize landraces within foreseeable future.
Diversity of maize (Z. mays L.) is usually studied to determine the crop variability and to evaluate the existing germplasm for breeding proposes, to identify and classify local and conservation landraces, or to detect needed morphological and agronomic traits. Goodman applied first multivariate analysis to study the maize diversity (Goodman 1967; Goodman and Paterniani 1969). Numerical taxonomy was previously used in the evaluation of maize populations and morphological traits (Brandolini and Brandolini 2001; Sanchez and Goodman 1992; Llauradó and Moreno-Gonzalez 1993; Goodman and Bird 1977). These methods have been applied either to identify maize landraces (Ruiz de Galarreta and Alvarez 2001; Sanchez and Goodman 1992) or to recognize the variability within the landraces (Herrera et al. 2004). The characters used in the present work were essentially those used in previous studies by Brandolini and Brandolini (2001), Malosetti and Abadie (2001), Ruiz de Galarreta and Alvarez (2001), Camussi (1979), Goodman and Bird (1977) or recommended by the IPGRI (2000). An earlier classification of ten Portuguese maize landraces was undertaken by Costa-Rodrigues (1971) on the basis of morphological and reproductive characters among 163 populations.

Maize is an important crop in Portuguese agriculture, whereas in 180.000 ha produce $850.000 \mathrm{t}$ grains per year, and more than $80 \%$ of the production is based on commercial hybrids or transgenic maize (DG AGRI 2003). The comparison of the culture situation shows that in Portugal mainland, the old landraces have been replaced by the commercial hybrids, when at Madeira the production is still based on open-pollinated cultivars. Although some missions have been conducted by external organizations to collect maize germplasm, the ISOPlexis/Germobanco, maintains the biggest and the most complete collection of the crop from Madeira. An analysis of the variability of Madeiran maize cultivars focusing on their morphological characterization is of great importance for performing the evaluation of crop diversity and identification of local landraces. The identification of local landraces will be useful to preserve the genetic variability, as well as to promote their use and will provide economical profits to farmers. At the same time, the evaluation of the genetic variability focused on traits of economic interest is useful for choosing the appropriate material 
for crop improvement in breeding programmes. According to our best knowledge characterization and evaluation of the Madeiran maize germplasm based on morphological variability and identification local landraces have never been performed. This work aims to characterize the maize germplasm through its morphological characterization, which allow us to establish core germplasm collections and a system for crop landraces identification.

\section{Materials and methods}

Plant material

A series of germplasm-collecting missions took place from October 1999 to October 2000 at the Madeira and Porto Santo Islands (Fig. 1). A set of 43 openpollinated populations 25 belonging to white and 18 to yellow maize representing the existing crop diversity has been selected. Seeds were collected from well-established traditional open-pollinated cultivars grown by local farmers for at least two family generations (about 40 years). A minimum sample of 20 ears representing variability was collected for each accession (Table 1).
Evaluation trials

The selected accessions were planted during the summer of 2001 and 2002 in the experimental farm at the University of Madeira, Funchal, at the beginning of February and yielded during June. Maize accessions were cultivated, according to traditional Madeiran farmers, with a strong application of organic manure before the planting and without mineral fertilizations, during the experience. During plant growth all blocks were irrigated once per day. All entries were grown in randomised complete block designs with two replications. The experimental units were a two row plots, with a row spacing of $90 \mathrm{~cm}$ and a row length of $6 \mathrm{~m}$. The trials were over planted and thinned manually to 20 plants per row with a plant density of 7.4 plants $\mathrm{m}^{2}$. In each plot, data of 41 morphological traits were taken on ten randomly selected competitive plants per plot. These traits were related with plant architecture (12), ear morphology (11), tassel morphology (7) and grain morphology (11) (Table 2). Plant height was measured from ground level to the tassel tip. Total leaf number and ear height were measured after flowering. Tassel length was measured from the point of origin of the lowermost branch to the tip of the central spike, and

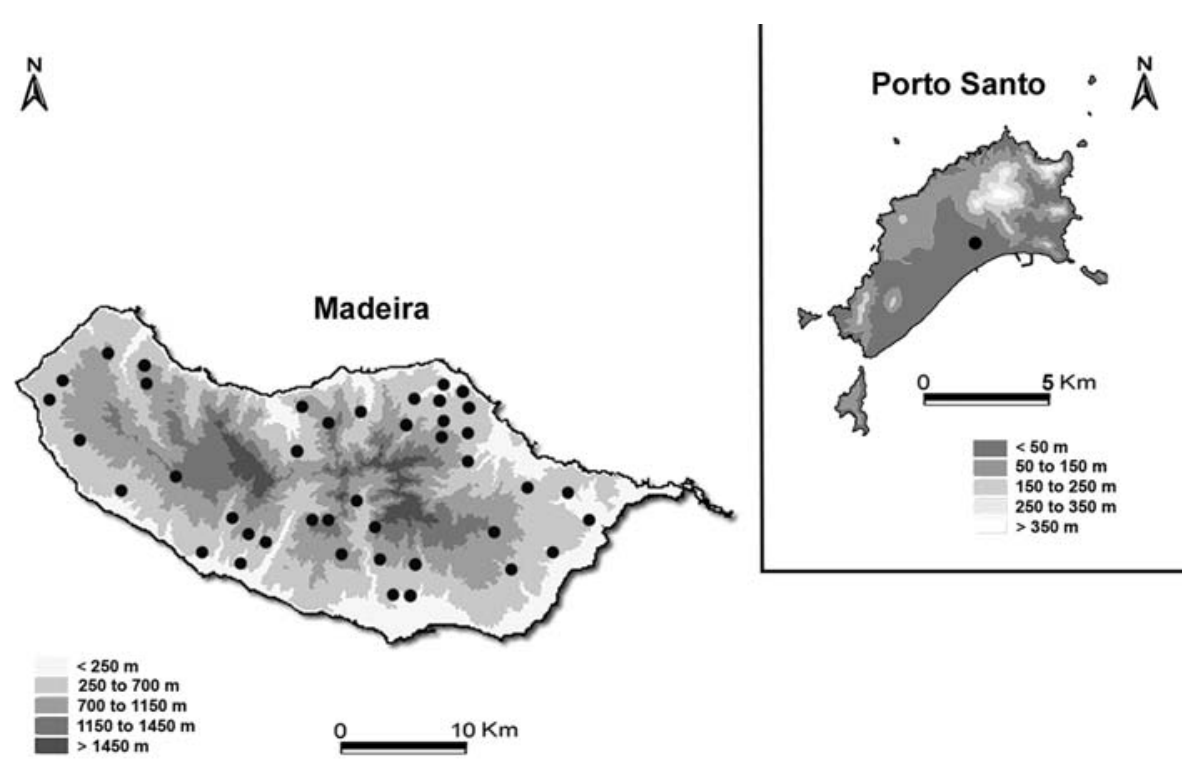

Fig. 1 Collection sites for the 43 Madeiran maize accessions discussed in this publication 
Table 1 Number of local populations, variety, origin and altitude of the Madeiran maize germplasm

\begin{tabular}{|c|c|c|c|}
\hline Population no. & Variety & Geographical origin & Altitude, $\mathrm{m}$ \\
\hline 1 & Yellow & Sta. Cruz & 236 \\
\hline 2 & White & Santana & 240 \\
\hline 3 & White & P. Sol & 589 \\
\hline 4 & Yellow & Calheta & 538 \\
\hline 5 & White & Santana & 663 \\
\hline 6 & White & $\mathrm{C}^{\mathrm{a}}$ Lobos & 448 \\
\hline 7 & Yellow & R. Brava & 950 \\
\hline 8 & White & Santana & 579 \\
\hline 9 & White & Santana & 328 \\
\hline 10 & White & Santana & 420 \\
\hline 11 & White & Santana & 661 \\
\hline 12 & White & Sta. Cruz & 686 \\
\hline 13 & White & Calheta & 715 \\
\hline 14 & Yellow & R. Brava & 458 \\
\hline 15 & White & S. Vicente & 198 \\
\hline 16 & Yellow & R. Brava & 446 \\
\hline 17 & White & R. Brava & 500 \\
\hline 18 & Yellow & S. Vicente & 88 \\
\hline 19 & Yellow & P. Santo & 69 \\
\hline 20 & White & S. Vicente & 450 \\
\hline 21 & Yellow & S. Vicente & 500 \\
\hline 22 & White & Sta. Cruz & 200 \\
\hline 23 & Yellow & Machico & 600 \\
\hline 24 & Yellow & Machico & 752 \\
\hline 25 & White & P. Moniz & 400 \\
\hline 26 & Yellow & Calheta & 513 \\
\hline 27 & Yellow & Calheta & 423 \\
\hline 28 & Yellow & P. Moniz & 389 \\
\hline 29 & Yellow & Santana & 310 \\
\hline 30 & White & P. Sol & 780 \\
\hline 31 & Yellow & Calheta & 344 \\
\hline 32 & White & P. Sol & 600 \\
\hline 33 & Yellow & R. Brava & 500 \\
\hline 34 & White & Câmara de Lobos & 600 \\
\hline 35 & Yellow & Câmara de Lobos & 400 \\
\hline 36 & White & P. Sol & 600 \\
\hline 37 & White & Câmara de Lobos & 523 \\
\hline 38 & White & Santana & 591 \\
\hline 39 & White & Santana & 300 \\
\hline 40 & White & Santana & 392 \\
\hline 41 & White & Machico & 212 \\
\hline 42 & Yellow & P. Sol & 343 \\
\hline 43 & White & P. Moniz & 430 \\
\hline
\end{tabular}


all primary, secondary and tertiary branches were counted, independently of their size. The nervation index, leaf area, plant height index, and branching index were calculated according to Brandolini and Brandolini (2001, Table 2).

Table 2 Morphological traits considered in the study of Madeiran maize germplasm

\begin{tabular}{|c|c|}
\hline Abbreviations & Trait \\
\hline ALP & Plant height $(\mathrm{cm})$ \\
\hline ALE & Plant height until the upper ear $(\mathrm{cm})$ \\
\hline FAE & Number of leaves above the upper ear \\
\hline $\mathrm{RB}$ & Shoots number \\
\hline PL & Hairs \\
\hline NF & Row number \\
\hline M_TG & Kernel type \\
\hline M_CG & Kernel colour \\
\hline NFL & Leaf number \\
\hline $\mathrm{CPF}$ & Leaf length $(\mathrm{cm})$ \\
\hline LGF & Leaf width $(\mathrm{cm})$ \\
\hline $\mathrm{IDN}^{\mathrm{a}}$ & Nervation index \\
\hline M_OF & Leaf orientation \\
\hline CPP & Tassel length $(\mathrm{cm})$ \\
\hline CPPD & Tassel peduncle length $(\mathrm{cm})$ \\
\hline CPRP & Tassel branching length $(\mathrm{cm})$ \\
\hline $\mathrm{RP}$ & First branches number \\
\hline $\mathrm{RS}$ & Second branches number \\
\hline RT & Third branches number \\
\hline $\mathrm{CPE}$ & Ear length $(\mathrm{cm})$ \\
\hline CPPDE & Ear peduncle length $(\mathrm{cm})$ \\
\hline DE & Ear diameter $(\mathrm{cm})$ \\
\hline DS & Ear pith diameter $(\mathrm{cm})$ \\
\hline DR & Ear rachis diameter $(\mathrm{cm})$ \\
\hline NB & Husks number \\
\hline NGF & Number of kernels per row \\
\hline M_CS & Pith colour \\
\hline M_FMMA & Upper ear shape \\
\hline DG & $\%$ Not developed kernels by ear \\
\hline CPG & Kernel length (mm) \\
\hline LGG & Kernel width (mm) \\
\hline ESG & Kernel thickness (mm) \\
\hline M_FG & Kernel shape \\
\hline M_CPC & Pericarp colour \\
\hline M_CAL & Aleurone colour \\
\hline M_CED & Endosperm colour \\
\hline PMG & Dry weight of 1,000 kernels $(\mathrm{g})$ \\
\hline IDALT $^{\mathrm{b}}$ & Plant height index $(\mathrm{cm})$ \\
\hline
\end{tabular}

Table 2 continued

\begin{tabular}{ll}
\hline Abbreviations & Trait \\
\hline $\mathrm{AF}^{\mathrm{c}}$ & Leaf area $\left(\mathrm{cm}^{2}\right)$ \\
$\mathrm{IDR}^{\mathrm{d}}$ & Branching index \\
$\mathrm{VSG}$ & Kernel volume $\left(\mathrm{cm}^{3}\right)$
\end{tabular}

Calculated according with Brandolini and Brandolini (2001), as follows:

a Nervation index (number of nervures divided by LGF)

b Plant height index (ALE divided by ALP)

c Leaf area (3/4 of LGF multiplied by CPF)

${ }^{d}$ Branching index (sum of RP, RS, RT multiplied by CPRP/CPP)

Statistical analysis

Mean values, standard deviation and variation indices were computed for each independently and for all accessions. The Kaiser-Meyer-Olkin (KMO) test was performed to determine the adequacy of maize sampling. Principal Components Analysis (PCA) as outlined according to Pinheiro de Carvalho et al. (2004b) and Llauradó and Moreno-Gonzalez (1993), and was used as an objective method to summarise variability of the 43 accessions. Factor analysis of mean values, based on Eigen-values was performed, using SPSS for Windows version 11.0, following Kinnear and Gray (1999). Principal Coordinates Analysis (PCO), using the Gower general similarity coefficient was performed to summarise variation and discriminate the weight of qualitative characters using MVSP for Windows version 3.13d, as referred by Kovach (1999). Maize accession clusters were compared through the Tukey tests and discriminant analysis to evaluate their independence. Both analyses were carried out to analyse the relationships among the groups and to identify the subset of traits and variables that best distinguish populations and clusters. Student $t$-tests were performed to evaluate the differences in values for single traits between the possible landraces. Goodman's racial criterion has been used to establish the landrace rank of the clusters through the calculation of the Mahalanobis distance between them using the first five case scores obtained from the PCO analysis (Eigen-values $\geq 0.5$ ). The Mahalanobis distance was represented through the un-weighted pair group method using arithmetic averages (UPGMA), the software program MatLab 7.0 (Sigmon 1993) was used in this analysis. 


\section{Results}

The variability of the collected maize germplasm was evaluated based on the study of 43 openpollinated populations belonging to the white or yellow flint maize. The average values for the quantitative morphological traits for all crop populations, as well as for both groups of white and yellow maize are shown in Table 3. Traits showed a large range of variability, particularly in plant height
(ALP), leaf area (AF), ear length (CPE), number of kernels per row (NGF), weight of 1,000 kernels (PMG), and kernel volume (VSG). Ear type was consistent with the eight-rowed flints with an average row number (NF) of 8, ranging from 7.3 to 13.1 throughout all samples. Ear shape varied from cylindrical to conical, with length ranging from 11.3 to $22.5 \mathrm{~cm}$ and diameter (DE) from 2.5 to $5.4 \mathrm{~cm}$. Kernel types, with a strong prevalence of flint type (M_TG) and colour (M_CG) varying from

Table 3 Variability of morphological traits of Madeiran maize germplasm

\begin{tabular}{|c|c|c|c|}
\hline Traits & Mean values & Mean values & Mean values \\
\hline ALP & $212.7 \pm 46.6$ & $223.0 \pm 46.1$ & $198.2 \pm 44.7$ \\
\hline ALE & $99.4 \pm 39.1$ & $109.9 \pm 42.3$ & $84.9 \pm 29.6$ \\
\hline FAE & $5.5 \pm 0.6$ & $5.8 \pm 0.6$ & $5.2 \pm 0.5$ \\
\hline $\mathrm{RB}$ & $1.7 \pm 1.0$ & $1.8 \pm 1.2$ & $1.4 \pm 0.6$ \\
\hline $\mathrm{NF}$ & $8.6 \pm 1.2$ & $8.7 \pm 1.0$ & $8.5 \pm 1.4$ \\
\hline NFL & $10.9 \pm 1.8$ & $11.5 \pm 1.8$ & $10.0 \pm 1.4$ \\
\hline $\mathrm{CPF}$ & $108.0 \pm 12.6$ & $110.2 \pm 11.4$ & $104.9 \pm 13.8$ \\
\hline LGF & $8.7 \pm 1.9$ & $9.6 \pm 1.8$ & $7.5 \pm 1.4$ \\
\hline IDN & $2.3 \pm 0.5$ & $2.3 \pm 0.3$ & $2.4 \pm 0.7$ \\
\hline CPP & $55.3 \pm 16.6$ & $54.3 \pm 17.7$ & $56.7 \pm 15.4$ \\
\hline CPPD & $28.1 \pm 6.5$ & $27.9 \pm 5.8$ & $28.2 \pm 7.5$ \\
\hline CPRP & $26.3 \pm 11.5$ & $26.7 \pm 12.3$ & $25.8 \pm 10.7$ \\
\hline $\mathrm{RP}$ & $10.7 \pm 3.2$ & $11.5 \pm 3.8$ & $9.5 \pm 1.8$ \\
\hline $\mathrm{RS}$ & $1.8 \pm 0.9$ & $2.1 \pm 0.9$ & $1.4 \pm 0.8$ \\
\hline RT & $0.4 \pm 0.7$ & $0.3 \pm 0.4$ & $0.4 \pm 0.9$ \\
\hline CPE & $16.1 \pm 3.0$ & $17.2 \pm 3.2$ & $14.5 \pm 2.0$ \\
\hline CPPDE & $5.4 \pm 3.3$ & $6.2 \pm 3.7$ & $4.4 \pm 2.3$ \\
\hline $\mathrm{DE}$ & $4.0 \pm 0.5$ & $4.2 \pm 0.5$ & $3.8 \pm 0.5$ \\
\hline DS & $2.5 \pm 0.4$ & $2.6 \pm 0.4$ & $2.4 \pm 0.3$ \\
\hline DR & $1.7 \pm 0.3$ & $1.8 \pm 0.3$ & $1.6 \pm 0.3$ \\
\hline NB & $9.4 \pm 2.1$ & $9.9 \pm 2.1$ & $8.7 \pm 2.1$ \\
\hline NGF & $26.8 \pm 6.8$ & $29.6 \pm 7.0$ & $23.2 \pm 4.6$ \\
\hline DG & $15.4 \pm 9.0$ & $13.7 \pm 7.8$ & $17.8 \pm 10.1$ \\
\hline $\mathrm{CPG}$ & $9.6 \pm 1.6$ & $9.8 \pm 1.7$ & $9.3 \pm 1.5$ \\
\hline LGG & $11.7 \pm 1.5$ & $12.0 \pm 1.3$ & $11.5 \pm 1.7$ \\
\hline ESG & $4.4 \pm 0.5$ & $4.5 \pm 0.6$ & $4.3 \pm 0.4$ \\
\hline PMG & $373.0 \pm 86.3$ & $400.9 \pm 74.9$ & $334.5 \pm 88.2$ \\
\hline IDALT & $0.5 \pm 0.1$ & $0.5 \pm 0.1$ & $0.4 \pm 0.1$ \\
\hline $\mathrm{AF}$ & $714.4 \pm 206.1$ & $797.0 \pm 190.0$ & $599.8 \pm 173.6$ \\
\hline IDR & $5.9 \pm 2.4$ & $6.6 \pm 2.6$ & $5.2 \pm 1.9$ \\
\hline VSG & $29.8 \pm 7.1$ & $31.8 \pm 6.7$ & $27.2 \pm 6.4$ \\
\hline
\end{tabular}

Table shows the mean values and standard deviation (SD) for all 43 accessions (second column), 25 white accessions (third column) and 18 yellow accessions (fourth column), which compose the two maize groups. The units of the measurements the same as in Table 2 

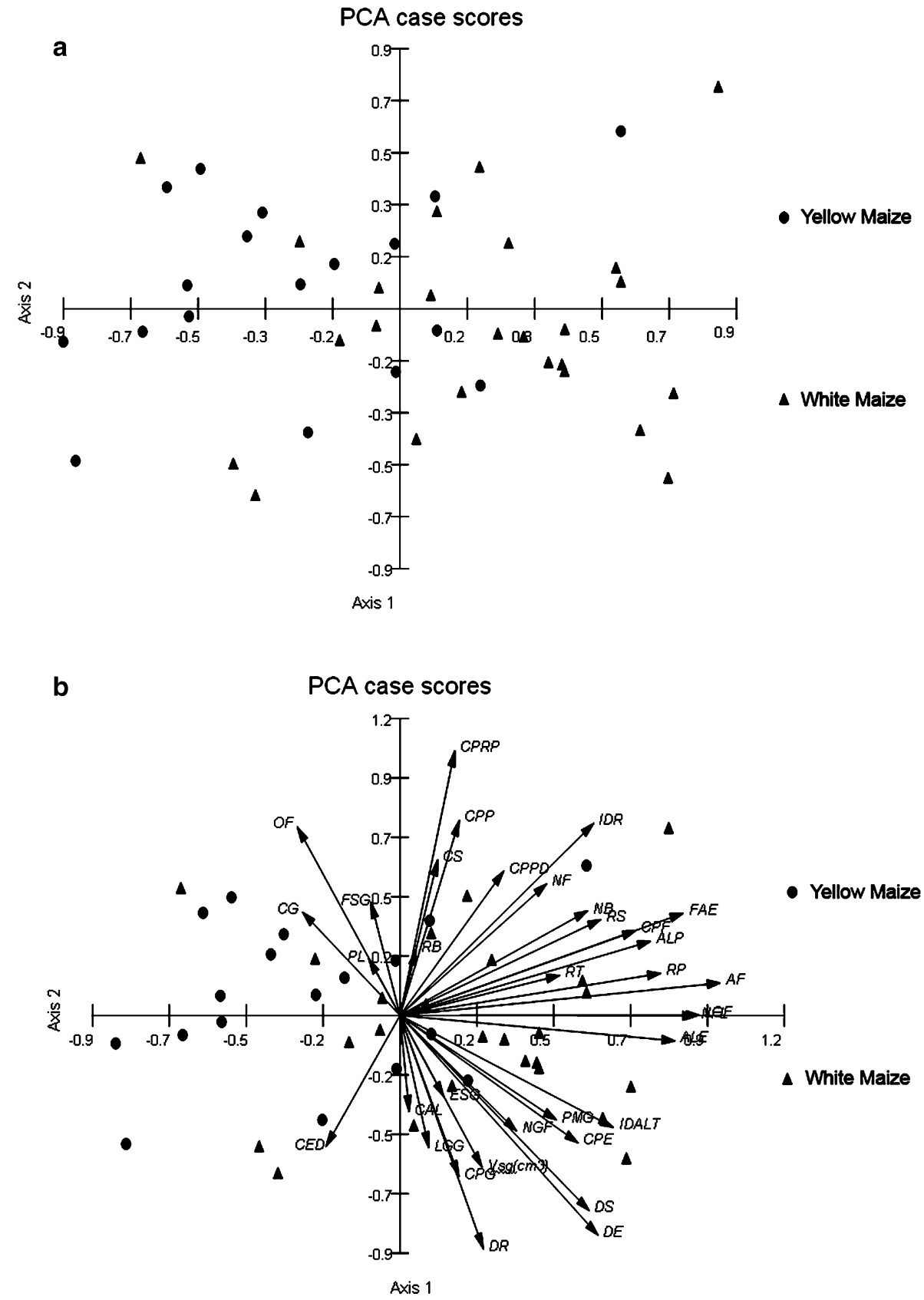

Fig. 2 Principal Component Analysis of maize populations. (a) Analysis explains $31.8 \%$ of observed field variability. Axis 1 explains $20.6 \%$ and Axis $211.1 \%$ of variability. Cumulative

white to yellow or rarely red. This variability is not surprising because the accessions were colleted from environments ranging from the sea level to 780 masl and represent the maximum field crop morphological variability (Table 1). The comparison of the morphological traits variation of white and yellow
Eigen-values have 13.0. (b) Eigenvectors show the contribution of morphological traits to the accessions separation

maize populations (Table 3) shown that most significant differences were related to ALP, AF, NGF, PMG and VSG parameters. The specimens of white maize were taller and more productive, having higher leaf areas and ears with more and heavier grain, when compared to the yellow maize. 


\section{PCO case scores (Gower General Similarity Coefficient)}

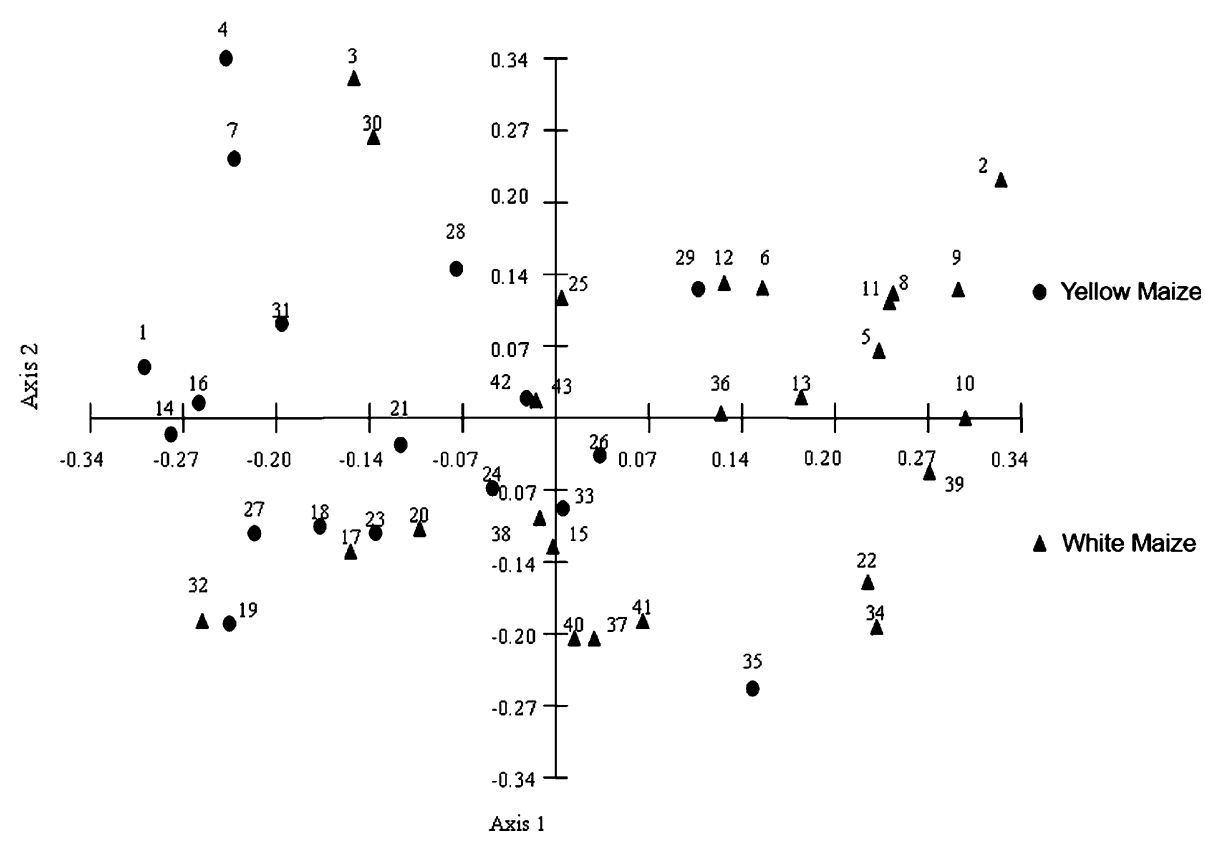

Fig. 3 Principal Coordinates Ordination of maize populations of Madeira. PCO analysis explains $20.9 \%$ of observed field variability. Axis 1 explains $12.7 \%$ and Axis $28.2 \%$ of variability. Cumulative Eigen-values have 2.5

The KMO analysis performed on the all accessions morphological data resulted in a value of 0.5 , which indicates an adequate plant sampling, allowing us to perform the PCA analysis. The morphological variability is explained and spread among 13 axes, but only the two first axes have a significant contribution to the accessions spatial distribution. This analysis divided the accessions along first two PCA axes, which explained $31.8 \%$ of the total variability (Fig. 2a). The Eigen-values sum for the both axes was 13.0, from a total value of 33.0. Figure $2 b$ pointed to the contribution of the morphological and reproductive traits to the spatial separation of the maize accessions. The PCO analysis using the Gower general similarity coefficient to discriminate qualitative from quantitative characters demonstrated an increase of the discontinuity of the accessions (Fig. 3). The separation along both PCO axes explains $20.9 \%$ of the observed variability. The third axis has been omitted due to an insignificant contribution to the explanation of the total variation. The Eigen-values sum for both axes is 2.5, from a total value of 12.3 .

The results of PCA and PCO analysis have been used to cluster and classify analysed maize accessions according to their belonging to yellow or white flint varieties. The discriminant analysis revealed that $93.0 \%$ of the accessions have been well classified. However, the spatial distribution of accessions allowed us to hypothesize the existence of several groups within the maize varieties. Figure 4 illustrates the performed PCO analysis with all maize accessions classified into four groups. The testing of this classification through the discriminant analysis revealed that in $95.3 \%$ of cases accessions have been well classified and still correctly classified in $88.4 \%$ of the cases after group cross-validation. For such proposes, the maximum degree of dissimilarity was determined using the Mahalanobis generalized distance, whereas the first two canonical variables explained $96.8 \%$ of the variability (data not shown).

The classification of uncertain cases has been check out and maintained or changed according to the consistence of the variability of their morphological traits. Significant morphological traits for accessions clustering into these groups were determined using the Tukey test and are summarised in Table 4. In this analysis, only quantitative traits were considered. The obtained results confirmed existence of the dissimilarity between groups and shown that they could be 


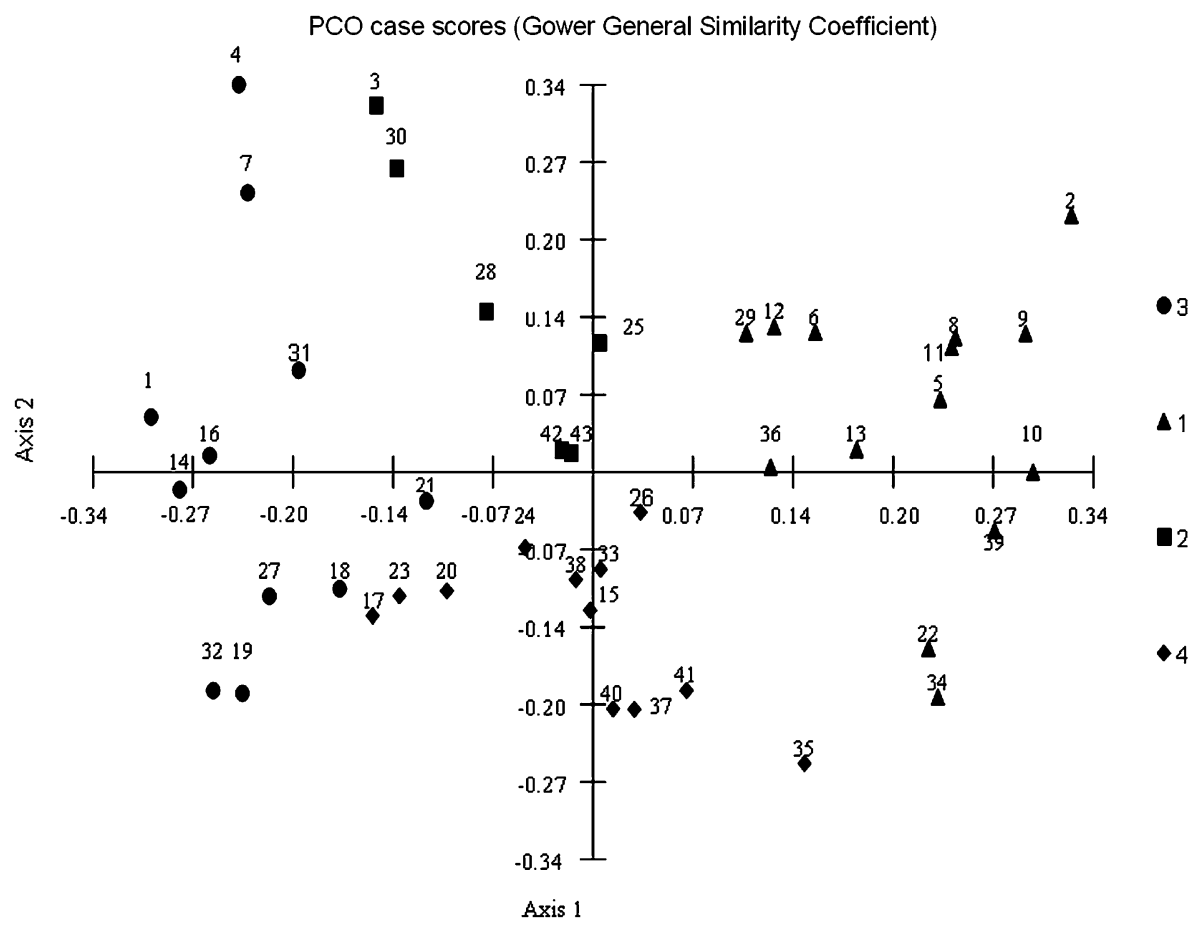

Fig. 4 Principal Coordinates Ordination of all 43 maize populations of Madeira. Analysis explains $22.4 \%$ of observed field variability. Axis 1 explains $13.4 \%$ and Axis $28.8 \%$ of variability. Cumulative Eigen-values have 2.4

distinguished by several significant morphological and reproductive traits. However, the major differences were observed between the group 1 when compared with groups 3 or 2 , or between 4 when compared with groups 3 or 1 . The smallest differences were observed between the groups 2 and 4 . The traits better correlating with the canonical variables were used to identify and describe the maize groups, which showed the following characteristics:

- Group 1, the largest group composed of 14 populations of white maize, majority originating from the North part of Madeira. The tallest plants $(240.7 \mathrm{~cm})$, with the largest leaf area $\left(914.2 \mathrm{~cm}^{2}\right)$, showed long tassels and long cylindrical or cylindrical-conical ears $(17.9 \mathrm{~cm})$, an average number of 8 kernels rows, varying from 8 to 12 rows, with heavy kernel weight $(403.7 \mathrm{~g})$ and high volume $\left(31.8 \mathrm{~cm}^{3}\right)$.

- Group 2, the smallest group composed of six populations of white maize collected from the northeaster part of the island. The plants were small $(186.6 \mathrm{~cm})$, with medium leaf area $\left(631.9 \mathrm{~cm}^{2}\right)$, medium-long tassels and cylindrical-conical ears $(16.6 \mathrm{~cm})$, with an average number of eight kernels rows, varying from eight to ten rows. Kernels had the heaviest weight $(434.3 \mathrm{~g})$ and the highest volume $\left(36.2 \mathrm{~cm}^{3}\right)$.

- Group 3, this group includes 11 populations of yellow maize from around the Island of Madeira and Porto Santo. Plants were smaller $(178.7 \mathrm{~cm})$, with small leaf area $\left(488.7 \mathrm{~cm}^{2}\right)$, medium-small tassels and cylindrical ears $(13.6 \mathrm{~cm})$, with an average number of 8 kernels rows, varying from 6 to 12 rows. Plants had the smallest kernel weight $(294.3 \mathrm{~g})$ and volumes $\left(25.9 \mathrm{~cm}^{3}\right)$.

- Group 4, 12 populations of yellow and white maize from around the island, which usually were named by local farmers as mixtures. Plants were medium tall $(224.0 \mathrm{~cm})$, with medium-large leaf area $\left(729.6 \mathrm{~cm}^{2}\right)$ and medium tassels and cylindrical-conical ears $(15.9 \mathrm{~cm})$, with an average number of 8 kernel rows, varying from 6 to 14 rows. Plants had medium kernel weight $(379.0 \mathrm{~g})$ and volumes $\left(28.2 \mathrm{~cm}^{3}\right)$. 
Table 4 Mean values of significant plant traits for four clusters of maize populations according to discriminate analysis

\begin{tabular}{|c|c|c|c|c|c|c|c|c|}
\hline Traits & No. & Cluster 1 & No. & Cluster 2 & No. & Cluster 3 & No. & Cluster 4 \\
\hline $\mathrm{NFL}^{\mathrm{a}, \mathrm{b}, \mathrm{c}, \mathrm{e}, \mathrm{f}}$ & 14 & $12.9 \pm 1.0$ & 6 & $9.0 \pm 0.0$ & 11 & $9.3 \pm 0.8$ & 12 & $10.9 \pm 1.0$ \\
\hline $\mathrm{LGF}^{\mathrm{a}, \mathrm{b}, \mathrm{c}, \mathrm{f}}$ & 14 & $10.8 \pm 1.1$ & 6 & $8.1 \pm 1.3$ & 11 & $6.7 \pm 0.8$ & 12 & $8.6 \pm 1.4$ \\
\hline $\mathrm{AF}^{\mathrm{a}, \mathrm{b}, \mathrm{c}, \mathrm{f}}$ & 14 & $914.2 \pm 126.2$ & 6 & $631.9 \pm 103.7$ & 11 & $488.7 \pm 75.3$ & 12 & $729.6 \pm 166.7$ \\
\hline $\mathrm{FAE}^{\mathrm{a}, \mathrm{b}, \mathrm{e}, \mathrm{f}}$ & 14 & $6.0 \pm 0.5$ & 6 & $5.1 \pm 0.3$ & 11 & $4.9 \pm 0.3$ & 12 & $5.8 \pm 0.6$ \\
\hline $\mathrm{DE}^{\mathrm{b}, \mathrm{d}, \mathrm{e}, \mathrm{f}}$ & 14 & $4.3 \pm 0.4$ & 6 & $4.5 \pm 0.3$ & 11 & $3.4 \pm 0.4$ & 12 & $4.0 \pm 0.3$ \\
\hline IDALT $^{\mathrm{a}, \mathrm{b}, \mathrm{c}}$ & 14 & $0.6 \pm 0.1$ & 6 & $0.4 \pm 0.1$ & 11 & $0.4 \pm 0.1$ & 12 & $0.4 \pm 0.1$ \\
\hline $\mathrm{ALE}^{\mathrm{a}, \mathrm{b}, \mathrm{c}}$ & 14 & $135.9 \pm 40.9$ & 6 & $79.0 \pm 16.9$ & 11 & $68.9 \pm 12.9$ & 12 & $95.0 \pm 26.7$ \\
\hline $\mathrm{ALP}^{\mathrm{a}, \mathrm{b}, \mathrm{f}}$ & 14 & $240.7 \pm 46.1$ & 6 & $186.6 \pm 38.5$ & 11 & $178.7 \pm 31.4$ & 12 & $224.0 \pm 39.4$ \\
\hline $\mathrm{CPG}^{\mathrm{b}, \mathrm{d}, \mathrm{e}}$ & 14 & $10.0 \pm 1.1$ & 6 & $11.6 \pm 1.6$ & 11 & $8.5 \pm 0.5$ & 12 & $9.2 \pm 1.8$ \\
\hline $\mathrm{PMG}^{\mathrm{b}, \mathrm{d}, \mathrm{f}}$ & 14 & $403.7 \pm 71.5$ & 6 & $434.3 \pm 37.9$ & 11 & $294.3 \pm 75.2$ & 12 & $379.0 \pm 84.6$ \\
\hline $\mathrm{RP}^{\mathrm{a}, \mathrm{b}}$ & 14 & $13.3 \pm 3.5$ & 6 & $8.7 \pm 0.9$ & 11 & $8.3 \pm 1.9$ & 12 & $10.8 \pm 2.3$ \\
\hline $\mathrm{RS}^{\mathrm{a}, \mathrm{b}}$ & 14 & $2.5 \pm 0.7$ & 6 & $0.9 \pm 0.3$ & 11 & $1.3 \pm 0.8$ & 12 & $1.9 \pm 0.9$ \\
\hline $\mathrm{DS}^{\mathrm{a}, \mathrm{d}}$ & 14 & $2.8 \pm 0.3$ & 6 & $2.7 \pm 0.4$ & 11 & $2.2 \pm 3.4$ & 12 & $2.5 \pm 0.3$ \\
\hline $\operatorname{IDR}^{\mathrm{a}, \mathrm{e}}$ & 14 & $7.1 \pm 2.5$ & 6 & $3.9 \pm 2.5$ & 11 & $4.8 \pm 1.8$ & 12 & $6.8 \pm 1.7$ \\
\hline $\mathrm{CPF}^{\mathrm{b}, \mathrm{f}}$ & 14 & $113.6 \pm 12.6$ & 6 & $104.0 \pm 8.0$ & 11 & $97.2 \pm 9.2$ & 12 & $113.3 \pm 10.7$ \\
\hline $\mathrm{CPE}^{\mathrm{b}}$ & 14 & $17.9 \pm 3.4$ & 6 & $16.6 \pm 2.8$ & 11 & $13.6 \pm 1.5$ & 12 & $15.9 \pm 0.2$ \\
\hline $\mathrm{NB}^{\mathrm{b}}$ & 14 & $10.6 \pm 2.1$ & 6 & $8.9 \pm 2.3$ & 11 & $8.0 \pm 1.6$ & 12 & $9.6 \pm 1.9$ \\
\hline $\mathrm{NGF}^{\mathrm{b}}$ & 14 & $31.0 \pm 8.2$ & 6 & $25.8 \pm 5.8$ & 11 & $22.5 \pm 3.8$ & 12 & $26.7 \pm 5.3$ \\
\hline $\mathrm{VSG}^{\mathrm{d}}$ & 14 & $31.8 \pm 5.5$ & 6 & $36.2 \pm 6.3$ & 11 & $25.9 \pm 4.0$ & 12 & $28.2 \pm 8.2$ \\
\hline $\mathrm{CPP}^{\mathrm{c}}$ & 14 & $49.0 \pm 20.0$ & 6 & $55.8 \pm 11.9$ & 11 & $50.3 \pm 16.4$ & 12 & $66.9 \pm 7.4$ \\
\hline $\mathrm{CPRP}^{\mathrm{c}}$ & 14 & $21.7 \pm 11.7$ & 6 & $22.2 \pm 13.9$ & 11 & $25.2 \pm 11.6$ & 12 & $34.8 \pm 4.4$ \\
\hline
\end{tabular}

Characters and measurements are the same as in Table 2

Significant traits in cluster separation are signalled as follows:

a Separation of clusters 1 and 2

b Clusters 1 and 3

c Clusters 1 and 4

d Clusters 2 and 3

e Clusters 2 and 4

f Clusters 3

\section{Discussion}

The monitoring of the crop diversity revealed that almost all maize cultivated on the Archipelago of Madeira belongs to the flint white or yellow types. These results agree with earlier descriptions of the Madeiran crop resources (Silva and Meneses 1984). The evaluation of 43 crop accessions representing the existing diversity and cultivation conditions has been performed based on 41 morphological traits (Fig. 1, Tables 1,2). This study uses the morphological traits and the methodology recommended by the IPGRI (2000) and adopted by Llauradó and Moreno-González (1993), Brandolini and Brandolini (2001), Ruiz de Galarreta and Alvarez (2001) in the classification of Spanish and Italian open-pollinated landraces. Goodman and Paterniani (1969) has documented by the adequacy of morphological traits to identify and classify maize landraces. Goodman (1967) proposed a racial criterion based on the Mahalanobis distance, which allows distinguishing groups having landrace rank.

Using morphological and reproductive traits but two times more morphological parameters than Llauradó and Moreno-González (1993) and Ruiz de Galarreta and Alvarez (2001) we screened and measured the variability of the Madeiran maize accessions and clustered them into separate groups. The high morphological variability observed across the crop accessions reflected the open-pollinated 
nature of local cultivars and can result from their adaptation to local conditions and the continuous use of seeds maintained by the Madeiran farmers (Table 3). The white and yellow maize that prevail on the Madeira Archipelago appeared to be well adapted to local environmental and edaphic conditions, which make their use more attractive for the local farmers then the commercial hybrids. Crop accessions were collected from farmer's plots, with some edapho-ecological parameters, ranging from 69 to 780 masl, altitude, 386 (Porto Santo) to $2,300 \mathrm{~mm}$ per year average precipitation, 4.23 to 6.87 , soil $\mathrm{pH}$ (Pinheiro de Carvalho et al. 2003, 2004a). Different rotational and manure application practices used by the farmers in different parts of the Archipelago may have also contributed to the diversification of maize. It has been demonstrated that isolation of maize into locations having different environments was a source of diversification of crop resources (Collins 1930). We hypothesize that the diversity of edapho-ecological conditions and agricultural practices promoted the acclimation of maize cultivars and development of the local landraces among crop germplasm. Similar variability was detected among the Northern Spanish open-pollinated populations and the existence of several sub-racial groups as the result of adaptation to local environmental conditions has been reported (Llauradó and Moreno-González 1993). Ruiz de Galarreta and Alvarez (2001) showed a high broad-sense heritability of several plant morphological traits independently of ecological conditions, which seems to be the case of Madeiran maize variability. Multivariate and discriminant analysis allowed us to weight the morphological variability of white and yellow maize (Table 3, Figs. 2, 3) and to prove that the $93 \%$ accessions were correctly classified. All observed variability can be explained by the existence of four maize groups (Fig. 4), which cluster and correctly classify $95.3 \%$ of the accessions, and can be distinguish and described by 21 traits, 8 vegetative and 13 reproductive (Table 4 ). Several genes controlled these traits and in the case of reproductive ones they are not influenced by the environment (Lindstrom 1930). Ruiz de Galarreta and Alvarez (2001) described and classified seven landraces groups of the Northern Spain maize using a similar approach based on the morphological characterization of crop accessions. Authors identified valuables sources of germplasm for breeding and improvement of maize among 100 populations studied. In an earlier work we clarified the taxonomy of Semele, an endemic genus of Macaronesia, through the evaluation of morphological variability and used multivariate analysis to weight its importance in genus diversity (Pinheiro de Carvalho et al. 2004b). According to the Tukey and $t$-tests, the most distinct Madeiran maize groups were the groups 1, 2 and 3, which are significantly separated by the variation of ten common traits.

In order to clarify the rank of these maize groups we used the racial criterion of Goodman (1967) based on determination of the Mahalanobis distance between group centroides (Goodman and Paterniani 1969). In their distinction of maize landraces, Goodman and Paterniani (1969) attributed the highest taxonomic value to the variation of tassel, ear and grain traits. The racial criterion defines that a degree of dissimilarity between groups higher than $1(D>1)$ allows considering their racial (landrace) rank. Llauradó and Moreno-Gonzalez (1993) obtained in their evaluation of the Northern Spanish maize populations values of the Mahalanobis generalized distance less than the Goodman's racial criterion $(D>1)$. Nevertheless, they used these values to validate the existence of sub-racial groups in the Northern Spanish maize, which were separated by a large number of vegetative traits. The authors concluded that these groups resulted from an open-pollinated nature of cultivars, farmer's selection and their adaptation to climatic and environmental conditions (Llauradó and Moreno-Gonzalez 1993). The Northern Spanish sub-racial groups, as well as clusters

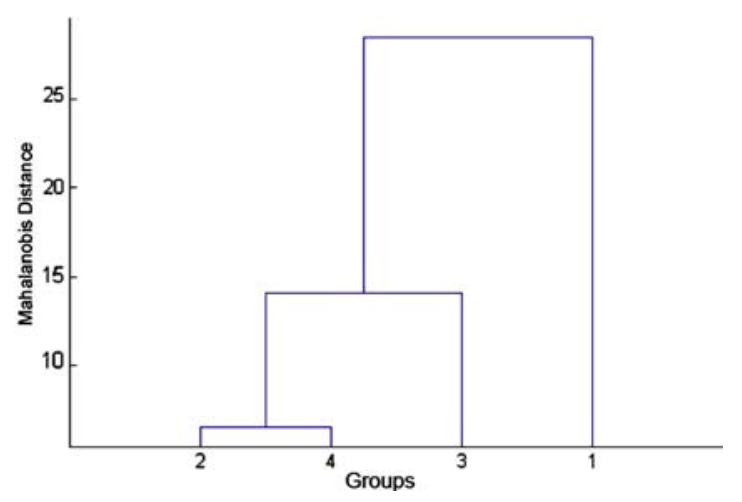

Fig. 5 Dendrogram showing the distances between the Madeiran maize landraces. The dendrogram was constructed using the UPGMA method and generalized Mahalanobis distances determined by MatLab 7.0 
obtained for the Italian varieties appeared to be associated with the geographical origin of their populations (Camussi 1979; Llauradó and MorenoGonzález 1993). The Mahalanobis distance between Madeiran maize groups was determined and a dendrogram constructed using the UPGMA method (Fig. 5). The maximum degree of dissimilarity observed among the population groups, which emerged in this study, was higher than the Goodman's racial criterion $(D>1)$ and ranges between 3.6 and 28.5. According to these results, maize groups had a racial rank and could be considered as conservation landraces based on the low number of ear rows. The observed dissimilarity between landraces was associated with a significant variation in reproductive traits of the ear, kernel and tassel. Their weight in landraces separation depended on each case, for example they had a great weight in the separation of landraces 1,2 and 3 , but were less important in the separation of landrace 4 or in other landraces cross-combinations. We tempt to conclude that the environmental conditions contributed to the development of maize landraces but they do not explain the observed variability and the existing crop diversity on the Archipelago of Madeira.

We can presume that group 1, essentially composed by white maize samples and with a relatively homogeneous distribution in the north side of the island, can represent the first maize introduction in Madeira, which is known to have occurred in Santana County, from varieties cultivated in the Azores Archipelago (Ribeiro 2001). In this group, plants have white kernels, conical-cylindrical ears, with an average of eight kernel rows, what seems to be characteristics of an older landrace. However, traits like taller plants, with long leaf and big kernels are result from a recent maize evolution and can be the result of succeeded adaptation of this landrace to local edaphic-ecological conditions. This group is well conserved in the North of the island, were topography made the access and communications difficult until the end of the XX century, and seeds were passed from generation to generation. The other important maize group, the group 3, is represented around the entire island. It could be the result of a latter maize introduction. This group has small plants, small leaf area, medium-small tassels, and cylindrical ears, with eight kernel rows, and the smallest kernel weight and volumes. The yellow flint corns are know to be more recent than white ones, so we can presume that group 1 represent a more ancient race than group 3. These are the two main landraces of Madeiran maize, well-distinguished one from the other. They probably resulted from different maize germplasm introductions, in distinct parts of the island. Groups 2 and 4 seemed to be variations of the previous groups, maybe due to adaptation to some local climatic or edaphic conditions, or even represent some form of farmer selection of the earlier groups. The fourth group is composed by samples know as "mixtures", and can be the result of crossings between groups. We can also presume that these groups, especially group 1, which was probably brought from Azores, can represent an old Portuguese variety of maize, that is already extinct in other regions of the country.

The only known attempt to characterize and identify the Portuguese maize landraces was made by Costa-Rodrigues (1971). This author identified ten maize landraces, named eight rows, microsperma, crossed microsperma, conical eight rows crossing, small conico, crossed conico, conico, big conico, large eared and gigantil. However, the large number of rows per ear allows us to hypothesize that with the exception of the eight rows landrace other accessions were not old landraces but have resulted from crosses within dent belt hybrids. Madeiran maize landraces identified in this work could share same similarities with Costa-Rodrigues eight rows landrace, which was originated from the Caribbean region. Other maize landraces existing in the Portuguese mainland are enumerated in "Portugal, country report" to the FAO Leipzig Conference (Barradas et al. 1995), and are named small yellow maize, 'orelha de lebre', 'unha de porco' 'verdeal', 'milhão', existing in the Northwest, and 'zorrinho', 'ratinho', 'gigante' and 'pinchorro' in the South of Portugal. These landraces are identified by specific morphological traits or for their geographical origin. The landraces 'orelha de lebre', 'verdeal', 'milhão', 'zorrinho' and 'gigante' seem to be correlated with the crossed microsperma, big conico, crossed conico, microsperma and gigantil Costa-Rodrigues landraces, respectively. Other attempts aiming at screening the Portuguese crop resources have been undertaken on 54 inbred lines of the Portuguese maize germplasm, but neither the morphological characterization nor landraces identification have been performed (Vaz Patto et al. 2004). 
Characterization of biochemical and agronomic traits of the Madeiran crop germplasm have also been conducted (De Freitas et al. 2005; Pinheiro de Carvalho et al. 2004a).

Despite of its small area, the Archipelago of Madeira due to the geographical isolation and diverse environmental, edaphic and agricultural conditions possesses unique crop resources, which diversity and germplasm should be evaluated and preserved. In conclusion, the performed morphological evaluation of the Madeiran maize germplasm reported herein reveals a significant genetic diversity. This can be a source of germplasm for crop improvement programmes. In this context, genetical classification of populations and landraces intimately associated with the origin of Madeiran maize can be applied towards minimizing the risk of genetic uniformity, ensuring long-term selection gain and partitioning a largely untapped source of material into new well-defined heterotypic groups, basic to Madeiran maize breeding. As results a first classification of the Madeiran maize landraces has been proposed. The obtained results will be used to define the core collections of this crop conserved at the ISOPlexis/Germobanco, as well as to preserve these landraces through their protection as maize conservation landraces.

Acknowledgements Portuguese Foundation for the Science and Technology (FCT, Fundação para a Ciência e Tecnologia) has sponsored this work, through the Centre of Macaronesian Studies (CEM) and the project POCTI no35003/AGR/2001. The Authors are grateful to the Madeiran farmers who assisted with collection of maize samples.

\section{References}

Barradas M, Bagulho F, Teixeira Duarte JM, Pereira OJ, Ferreira JT (1995) Landraces and old cultivars. Portugal: Country report to the FAO International Technical Conferences on Plant Genetic Resources. Ministry of Agriculture, Oeiras, pp 22-26

Brandolini A, Brandolini A (2001) Classification of Italian maize (Zea mays L.) germplasm. Plant Genet Resour News1 126:1-11

Camussi A (1979) Numerical taxonomy of Italian maize populations based on quantitative traits. Maydica 24:161-174

Collins GN (1930) The phylogeny of maize. Bull Torrey Bot Club 57(4):199-210

Costa-Rodrigues L (1971) Races of maize in Portugal. Agron Lusit 31:239-248

De Freitas LRA, Ganança JFT, Dos Santos TMM, Pinheiro de Carvalho MÂA, Motto M, Clemente Vieira MR (2005)
The use of seed proteins, zein, in the evaluation of Madeira maize germplasm. Maydica 50:105-112

DG Agricultura (2003) Situação da Agricultura em Portugal. Comissão Europeia, Bruxelas

Goodman MM (1967) The races of maize. The use of Mahalanobis generalized distances to measure morphological similarity. Fitotec Latinoam 4:1-22

Goodman MM, Bird RMCK (1977) The races of maize: IV. Tentative grouping of 219 Latin American races. Econ Bot 31:204-221

Goodman MM, Paterniani E (1969) The races of maize: III. Choices of appropriate characters for racial classification. Econ Bot 23:265-273

Herrera CBE, Castillo GF, Sanchez CJJ, Hernández CJM, Ortega PRA (2004) Diversidad del maíz Chalqueno. Agrociencia 38:191-206

IPGRI (2000) Descriptores de milho. FAO, Rome

Kinnear PR, Gray CD (1999) SPSS for Windows made simple. Psychology Press, East Sussex

Kovach WL (1999) MvsP-a multivariate statistical package for Windows, ver. 3.1. Kovach Computing Services, Pentraeth

Lindstrom EW (1930) The genetics of maize. Bull Torrey Bot Club 57(4):221-231

Llauradó M, Moreno-Gonzalez J (1993) Classification of northern Spanish populations of maize by methods of numerical taxonomy. I. Morphological traits. Maydica 38:15-21

Malosetti M, Abadie T (2001) Sampling strategy to develop a core collection of Uruguayan maize landraces based on morphological traits. Genet Resour Crop Evol 48:381-390

Paliwal RL, Granados G, Lafitte HR, Violic AD (2000) Tropical maize improvement and production. FAO Plant production and protection series, vol 28. FAO, Rome, Italy

Pinheiro de Carvalho MÂA, Slaski JJ, Dos Santos TMM, Ganança JFT, Abreu I, Taylor GJ, Clemente Vieira MR, Popova TN, Franco E (2003) Identification of aluminium resistant genotypes among Madeiran regional wheats. Commun Soil Sci Plant Anal 34(19-20):2967-2979

Pinheiro de Carvalho MÂA, Slaski JJ, Abreu I, Ganança FT, Dos Santos TMM, Freitas L, Clemente Vieira MR, Nunes A, Antunes A, Taylor G (2004a) Factors contributing to the development of aluminium tolerance in the Madeiran maize germplasm. J Plant Nutr Soil Sci 167:1-6

Pinheiro de Carvalho MÂA, Wilcock CC, Dos Santos TMM, Vale Lucas IC, Ganança JFT, Franco E, Thangadurai D, Rao D, Sousa NF (2004b) A review of the genus Semele (Ruscaceae) systematics in Madeira. Bot J Linn Soc 146(4):483-497

Ribeiro JA (2001) Santana. Homens e assuntos que a ilustram. CM de Santana, Santana

Ruiz de Galarreta JI, Alvarez A (2001) Morphological classification of maize landraces from northern Spain. Genet Resour Crop Evol 48:391-400

Sanchez JJ, Goodman MM (1992) Relationships among the Mexican races of maize. Econ Bot 46:72-85

Sigmon K (1993) MatLab primer, 3rd edn. University of Florida, Gainesville

Silva AF, Meneses CA (1984) Elucidário madeirense, vol 2. SRTC-DRAC, Funchal, p 363

Vaz Patto MC, Satovic Z, Pêgo S, Fevereiro P (2004) Assessing the genetic diversity of Portuguese maize germplasm using microsatellite markers. Euphytica 137(1):63-72 